DOI 10. 18307/2016. 0522

(C) 2016 by Journal of Lake Sciences

\title{
湛江湖光岩玛珥湖全新世粒度变化特征及古气候意义
}

\author{
吴旭东 ${ }^{1}$, 刘国旭 ${ }^{1}$, 沈 吉 ${ }^{2 * *}$ \\ (1: 南阳师范学院环境科学与旅游学院, 南阳 473061) \\ (2: 中国科学院南京地理与湖泊研究所湖泊与环境国家重点实验室，南京 210008)
}

\begin{abstract}
摘 要: 对湖光岩玛珥湖沉积物全新世粒度参数 $、 550^{\circ} \mathrm{C}$ 烧失量和 $\mathrm{Ti}$ 元素含量的变化特征研究后认为: 粒度频率特征曲 线指示湖光岩玛珥湖沉积物的外源输人部分主要来自其小流域; 沉积物粒径的变化主要受降雨量, 而不是湖泊水位波动 的控制; 较粗的粒径指示降雨量增加, 较细的粒径指示降雨量降低. 湛江地区全新世早期季风强盛, 6085 a B.P. 以后, 季风 显著减弱. 湖光岩沉积物记录的全新世中期季风迅速减弱的发生时间与全球很多地质载体记录的全新世中期季风迅速 减弱时间都非常接近,体现了湛江地区全新世季风演化的全球性. 湛江地区 6085 a B.P. 以后的季风迅速减弱、气候转干 很可能与厄尔尼诺活动增强有关. 2000 a B.P. 以后, 粒度参数 $550^{\circ} \mathrm{C}$ 烧失量和 $\mathrm{Ti}$ 元素含量的变幅明显增加与人类活动的 影响有关,是人类活动和气候因素共同作用的结果.
\end{abstract}

关键词: 粒度; 全新世; 古气候; 湖光岩玛珥湖

\section{Grain size variation and its environmental significance from Huguangyan Maar Lake, Zhanjiang since the Holocene}

\author{
WU Xudong ${ }^{1}$, LIU Guoxu ${ }^{1} \&$ SHEN Ji ${ }^{2 * *}$ \\ (1: School of Environment and Tourism Science, Nanyang Normal University, Nanyang 473061, P.R.China) \\ (2: State Key Laboratory of Lake Science and Environment, Nanjing Institute of Geography and Limnology, Chinese Academy \\ of Sciences, Nanjing 210008, P.R.China)
}

\begin{abstract}
Through investigation on grain size parameters, loss on ignition $\left(550^{\circ} \mathrm{C}\right)$ and Ti contents of Huguangyan Maar Lake sediment during the Holocene, frequency curve of grain size suggests that terrestrial input of Huguangyan Maar Lake are predominantly from its small catchment, and grain size variation of the sediment during the Holocene was determined by precipitation instead of lake level fluctuation, with coarser grain size indicating higher precipitation and finer grain size indicating lower precipitation. Asian monsoon at Zhanjiang area was strong in the early Holocene, and weakened substantially since 6085 a B.P.. The substantial weakening of Asian monsoon in the mid-Holocene recorded by Huguangyan Maar Lake sediment occurred at the time which was very close to the time of substantially weakened monsoon event recorded by many other archives around the globe, embodying globalization of monsoon evolution during the Holocene of Zhanjiang area. Weakened Asian monsoon and enhanced drought since 6085 a B.P. might be related to the enhanced ENSO activity. The amplitude of grain size parameters, loss on ignition $\left(550^{\circ} \mathrm{C}\right)$ and $\mathrm{Ti}$ content increased remarkably after 2000 a B.P., which may be due to intensified human activity and it is the result of both human activities and climate change.
\end{abstract}

Keywords: Sediment grain size; Holocene; Paleoenvironment; Huguangyan Maar Lake

湖光岩是位于中国大陆最南端——雷州半岛上的一个小型玛珥湖. 独特的地理位置使湖光岩成为古气

* 中国科学院战略性先导科技专项 (XDA05120102)、创新团队国际合作伙伴计划项目 (KZZD-EW-TZ-08)、河南省教 育厅重点项目 (14B170008)、南阳师范学院博士启动基金项目 (70636) 和国家自然科学基金项目 (41502165) 联合 资助. 2015-06-02 收稿;2015-10-17 收修改稿. 吴旭东 (1982 ), 女, 博士, 讲师; E-mail: wuxudong2013@aliyun. com.

** 通信作者; E-mail:jishen@ niglas.ac.cn. 
候研究的热点 ${ }^{[1-6]}$, 有关其 $\mathrm{Ti}$ 元素来源和环境意义的问题引起了学术界的剧烈争论 ${ }^{[7-10]}:$ Yancheva 等 ${ }^{[7]}$ 认为 湖光岩沉积物中的 $\mathrm{Ti}$ 元素是冬季风从黄土高原带来的风尘沉积. 然而, 周厚云等 ${ }^{[8]}$ 在比较了当地的玄武 岩、风化红土以及黄土的 $\mathrm{Ti}$ 含量之后提出湖光岩沉积物中的 $\mathrm{Ti}$ 主要来自于其小流域, 可能反映了湖泊水文 条件的变化. Yancheva 等 ${ }^{[9]}$ 认为如果 $\mathrm{Ti}$ 来自于流域的话, 就不能解释降雨量高的时期湖光岩沉积物中 $\mathrm{Ti}$ 元 素含量反而低的现象. 之后, 周厚云等 ${ }^{[10]}$ 发现湖光岩表层沉积物的 $\mathrm{REE} 、{ }^{87} \mathrm{Sr} /{ }^{86} \mathrm{Sr} 、{ }^{143} \mathrm{Nd} /{ }^{144} \mathrm{Nd}$ 与当地火山 岩和风化红土接近, 与黄土差距较大, 证明了湖光岩沉积物的物源是湖泊四周的小流域. 沈吉等 ${ }^{\left[{ }^{[1]}\right.}$ 对湖光 岩表层沉积物中来自流域径流输人和黄土高原风尘沉积 $\mathrm{Ti}$ 的比例做了估算, 确定了湖光岩沉积物 $\mathrm{Ti}$ 源为 其小流域,并提出全新世 $\mathrm{Ti}$ 元素含量变化反映了季风驱动下流域植被的变化.

作为沉积物的一项重要物理参数,粒度具有分析便捷、经济,基本不受生物扰动和后期成岩作用影响等优 势 ${ }^{[12]}$, 已被成功运用于多种类型沉积物的古气候研究中 ${ }^{[13-16]}$. 尽管前人已经在湖光岩做了大量古气候研究工 作, 但一直未见与粒度参数有关的报道, 这可能与湖光岩的物源问题一直没有搞清楚有关. 现在已经明确了湖 光岩沉积物的物源主要是其小流域,受水动力条件控制, 这为我们讨论粒度指标的环境意义奠定了基础. 然 而, 即使水动力是唯一沉积动力, 湖泊沉积物粒度指标的环境意义仍然存在两种解释. 第 1 种是: 当降雨量增 多, 湖面上升, 流域碎屑物质需要搬运较远的距离才能到达沉积中心点, 水动力条件减弱, 沉积物粒径变细; 当 降雨量减少, 湖面下降, 流域碎屑物质较容易到达沉积中心点, 水动力条件增强, 沉积物粒径变粗; 第 2 种是: 当 湖面比较稳定时, 降雨量高的阶段, 径流搬运能力强, 导致沉积物粒径变粗; 降雨量低的时候, 径流搬运能力 弱, 沉积物粒径变细 ${ }^{[17]}$. 因此, 需要与气候意义明确的指标对比才能确定不同湖泊粒度指标的环境意义.

本文将分析湖光岩玛珥湖全新世以来粒度参数的变化, 结合 $550^{\circ} \mathrm{C}$ 烧失量等气候意义明确的指标探讨 湖光岩沉积物中粒度参数的环境意义; 并利用粒度、 $550^{\circ} \mathrm{C}$ 烧失量和 $\mathrm{Ti}$ 元素含量变化重建全新世以来湛江地 区气候和湖光岩小流域环境演化过程.

\section{1 研究区与样品采集}

湖光岩玛珥湖 $\left(21^{\circ} 9^{\prime} \mathrm{N}, 110^{\circ} 17^{\prime} \mathrm{E}\right)$ 位于雷州半岛东北部, 广东省湛江市西南方向大约 $18 \mathrm{~km}$ 处 (图 $\left.1 \mathrm{~A}\right)$. 湛江地区属于亚热带海洋性季风气候, 干季 (10 月至次年 3 月)、湿季(4-9 月) 变化明显. 湖光岩湖水面积 2. $25 \mathrm{~km}^{2}$, 汇水面积 $3.2 \mathrm{~km}^{2}$, 最大水深 $22 \mathrm{~m}$, 平均水深 $12 \mathrm{~m}$, 既没有河流汇人, 也没有湖水流出. 湖光岩四周被高 笪的火山岩墙所包围, 其中南岸陡峭, 北岸较为平缓. 湖泊近似为心形, 一条南北走向的浅滩把它分成东西两 个部分,其中东湖小、西湖大 (图 1B). 周围的自然植被是半常绿季雨林, 土壤是玄武岩的风化产物.

2009 年 11 月在湖光岩玛珥湖西湖水深 $16.2 \mathrm{~m}$ 处 $\left(21^{\circ} 08^{\prime} 38^{\prime \prime} \mathrm{N}, 110^{\circ} 16^{\prime} 46^{\prime \prime} \mathrm{E}\right.$, 图 1B) 采集了岩芯 A( 855 $\mathrm{cm})$ 和 B $(926 \mathrm{~cm})$. 由于两根岩芯的采样位置距离仅为 $5.2 \mathrm{~m}$, 因此可以看做是完全一样的. 岩芯的上半部 是灰色黏土,下半部是腐殖黑泥.

\section{2 实验分析}

\section{1 测年研究}

在岩芯 B 选择了 24 个样品送往加利福尼亚大学进行 $\mathrm{AMS}^{14} \mathrm{C}$ 测年, 具体的选样深度、平行样设置、实验 流程和年龄校正方法在以往的研究中已经作了详尽的描述 ${ }^{[6]}$.

\section{2 粒度}

本研究环境指标分析使用的是岩芯 A. 在实验室内将岩芯沿中轴线剖开, 以 $1 \mathrm{~cm}$ 为间距采样, 共取得 855 个样品. 粒度前处理过程采用双氧水加盐酸的方法, 具体程序如下:

(1) 取适量样品于烧杯中, 加人 $5 \%$ 的双氧水 $\left(\mathrm{H}_{2} \mathrm{O}_{2}\right)$ 静置 $24 \mathrm{~h}$, 然后在 $80^{\circ} \mathrm{C}$ 下水浴加热, 根据有机质含 量的多少调整双氧水的用量, 直到完全去除样品中的有机质 (样品由黑色变为黄色).

(2) 加人 $5 \%$ 的盐酸 $\left(\mathrm{HCl}\right.$ ) 静置 $24 \mathrm{~h}$, 然后在 $80^{\circ} \mathrm{C}$ 下水浴加热直到没有气泡产生为止, 以除去样品中的 碳酸盐.

(3) 加足量去离子水使溶液呈中性, 静置样品, 直到所有颗粒全部沉降再除去上层清液.

(4) 加人 $10 \mathrm{ml}$ 浓度为 $0.05 \mathrm{~mol} / \mathrm{L}$ 的分散剂六偏磷酸钠 $\left(\left(\mathrm{NaPO}_{3}\right)_{6}\right)$, 超声波振荡 $15 \mathrm{~min}$ 后测试. 

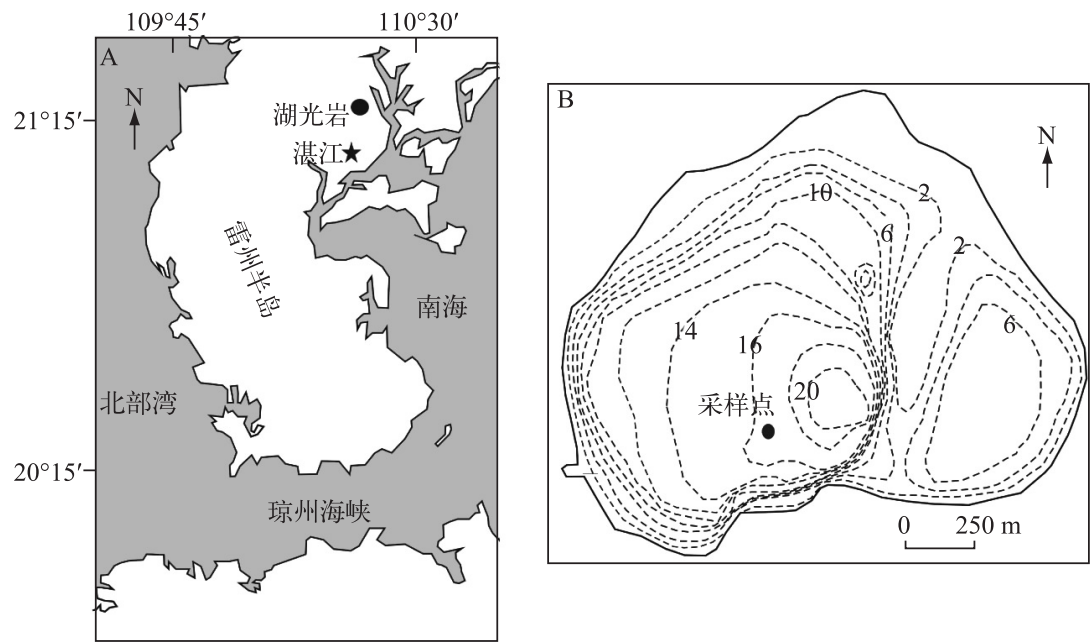

图 1 湖光岩玛珥湖地理位置 $(A)$ 和采样点位置及等深线图 (B, 图中数字代表水深, 单位为 $\mathrm{m})$

Fig. 1 Location of Huguangyan Maar Lake (A); Sampling position and isobaths map ( $\mathrm{B}$, numbers in part $\mathrm{B}$ represent water depth and the unit is $\mathrm{m}$ )

粒度分析的仪器是英国 Malvern 公司生产的 Mastersize 2000 型激光粒度仪, 测量范围为 $0.02 \sim 2000 \mu \mathrm{m}$, 重复测量误差小于 $1 \%$.

$550^{\circ} \mathrm{C}$ 烧失量 ${ }^{[18]}$ 和 $\mathrm{Ti}$ 元素含量 ${ }^{[11]}$ 的测试方法笔者已经在以前的研究中描述过.

\section{3 结果}

\section{1 年代}

湖光岩沉积物年代连续,无倒置现象, 岩芯年代随深度变化图见笔者已发表的文章 ${ }^{[6]}$.

\section{2 粒度}

利用粒度参数可以判断沉积物的搬运介质与机制、沉积环境与过程 ${ }^{[19]}$. 就湖泊沉积物而言, 粒度分布 频率曲线的单、双峰形态分别代表存在一种或两种搬运机制 ${ }^{[20-21]}$. 对封闭的玛珥湖来说, 其陆源碎屑物质主 要有两个来源: 一是流域范围内的径流输人, 二是大气降尘, 径流输人的物质颗粒较粗, 而大气降尘的物质 颗粒较细 ${ }^{[22]}$. 因此, 我们判断取自岩芯中部 (大约 $400 \mathrm{~cm}$ 深度) 沉积物的粒度频率特征曲线 (图 2) 中的小峰 代表的是大气降尘, 大峰代表的是径流输人, 湖光岩玛珥湖沉积物的外源输人部分主要来自流域径流输人, 大气降尘只占其中很小的一部分, 水动力是湖光岩沉积物的主要沉积动力. 虽然湖光岩玛㻓湖并没有河流 汇人, 但是其四周的火山岩墙与湖泊的相对高差较大, 并且坡度陡峭, 尤其是在湖光岩南岸. 在这种地形下, 碎屑物质很容易随坡面径流输人到湖泊中.

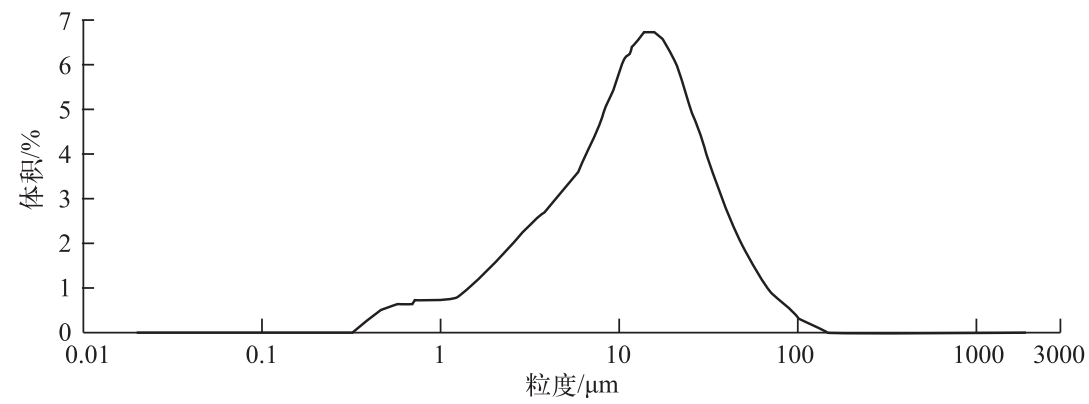

图 2 湖光岩玛珥湖沉积物粒度频率特征曲线

Fig.2 Frequency curve of sedimentary grain size from Huguangyan Maar Lake 
根据 Udden-Went-Worth 粒度划分方法将湖光岩玛珥湖沉积物粒度组分划分为 5 级,即: 黏土 $(<4 \mu \mathrm{m})$ 、 细粉砂 $(4 \sim 16 \mu \mathrm{m})$ 、中粉砂 $(16 \sim 32 \mu \mathrm{m})$ 、粗粉砂 $(32 \sim 64 \mu \mathrm{m})$ 、砂 $(>64 \mu \mathrm{m})$. 黏土含量在 $3.84 \% \sim 48.61 \%$ 之 间, 平均值为 $27.03 \%$; 细粉砂含量为 $25.24 \% \sim 53.74 \%$, 平均值为 $41.83 \%$; 中粉砂含量为 $7.37 \% \sim 34.55 \%$, 平 均值为 $21.93 \%$; 粗粉砂含量为 $1.34 \% \sim 26.24 \%$, 平均值为 $6.95 \%$; 砂含量在 $0 \sim 13.50 \%$ 之间, 平均值为 $2.25 \%$. 中值粒径在 $4.18 \sim 25.71 \mu \mathrm{m}$ 之间, 平均值是 $9.90 \mu \mathrm{m}$. 湖光岩玛珥湖沉积物的中值粒径在整个全新世呈逐渐 下降的趋势, 尤其是全新世晚期下降显著 (图 3 ). 中粉砂、粗粉砂和砂组分的比例在全新世内也呈逐渐下降 的趋势, 黏土组分的比例在全新世内呈逐渐上升趋势, 细粉砂组分的比例在全新世内没有明显波动 (图 3 ).

\section{$3.3550^{\circ} \mathrm{C}$ 烧失量}

湖光岩玛珥湖沉积物的 $550^{\circ} \mathrm{C}$ 烧失量在全新世呈下降趋势: 全新世早期 $550^{\circ} \mathrm{C}$ 烧失量最高; 自全新世中 期开始, $550^{\circ} \mathrm{C}$ 烧失量显著下降 ${ }^{[18]}$ ( 图 3 ).

\section{$3.4 \mathrm{Ti}$ 元素含量}

与中值粒径和 $550^{\circ} \mathrm{C}$ 烧失量相反, 湖光岩玛珥湖沉积物的 $\mathrm{Ti}$ 元素含量呈上升趋势: $\mathrm{Ti}$ 元素在全新世早 期最低; 从全新世中期开始, Ti 元素含量迅速升高, 尤其是 2000 a B.P.以后升高显著 ${ }^{[11]}$ ( 图 3 ).

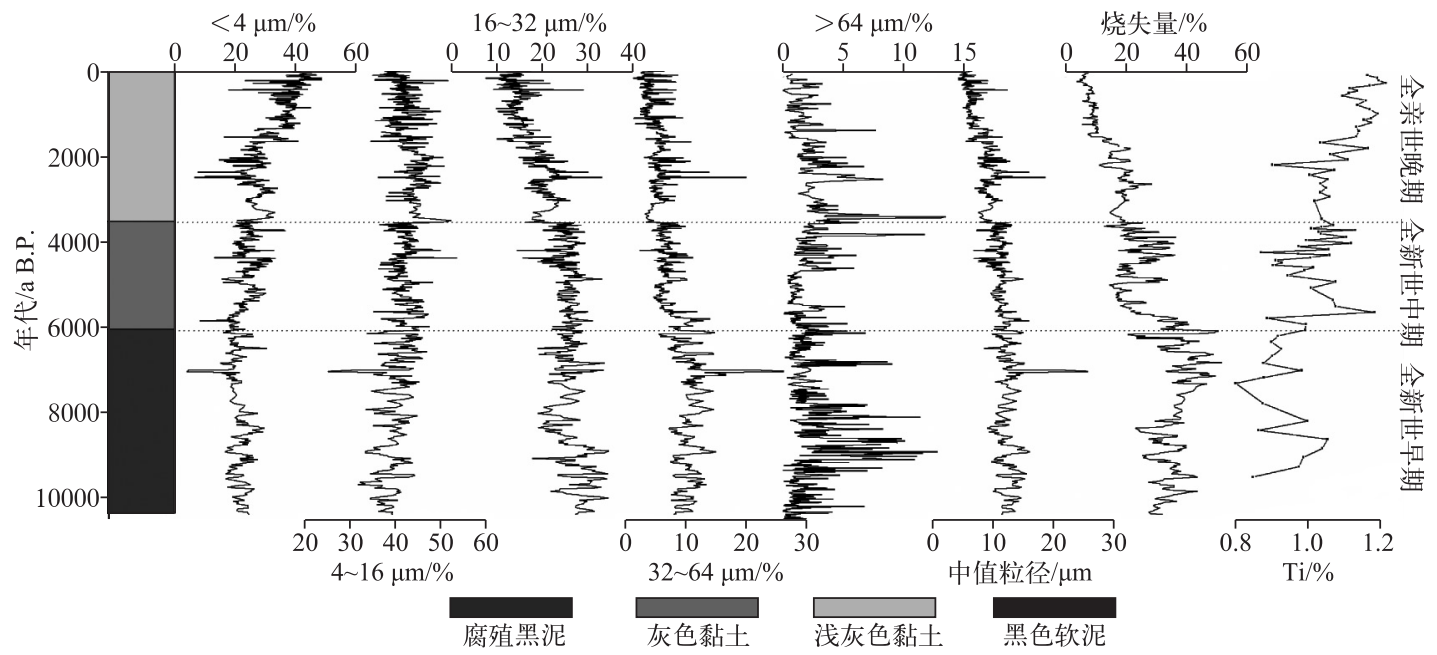

图 3 湖光岩玛珥湖沉积物岩性、各粒级组分含量、中值粒径、 $550{ }^{\circ} \mathrm{C}$ 烧失量 ${ }^{[18]}$ 和 $\mathrm{Ti}$ 元素含量 ${ }^{[11]}$

Fig.3 Lithology, contents of different particle-size fractions, median particle diameter, LOI $\left(550^{\circ} \mathrm{C}\right)^{[18]}$ and $\mathrm{Ti}$ contents ${ }^{[11]}$ of Huguangyan Maar Lake sediment

\section{4 讨论}

\section{1 环境指标的意义}

$550^{\circ} \mathrm{C}$ 烧失量反映了湛江地区全新世早期气候温暖湿润, 自全新世中期开始,气候明显转干 ${ }^{[18]}$.

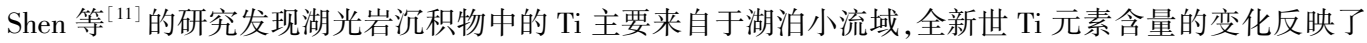
季风驱动下流域植被的变化 ${ }^{[17]}$. 从全新世早期到晚期, 逐渐升高的 $\mathrm{Ti}$ 反映了湛江地区季风不断减弱, 降雨 量持续下降, 流域植被恶化, 导致地表侵蚀作用加强 ${ }^{[8]}$.

湖光岩玛珥湖沉积物中值粒径的的变化趋势和 $550^{\circ} \mathrm{C}$ 烧失量一致, 而与 $\mathrm{Ti}$ 元素含量变化趋势相反 (图 3 ). 这说明湛江地区降雨量高的时期, 湖光岩沉积物由于径流搬运能力的增强而粒径较粗, 但是此时流域植 被发育较好, 因此地表侵蚀较弱. 此外, 中值粒径与 $550^{\circ} \mathrm{C}$ 烧失量呈正相关、与 $\mathrm{Ti}$ 元素含量呈负相关还说明 降雨量对湖光岩沉积物全新世粒度参数变化起主导作用,而湖泊水位波动对湖光岩沉积物粒度变化的影响 不大. 因此, 湖光岩沉积物较粗的粒径指示降雨量增加, 较细的粒径指示降雨量降低. 砂组分含量的变化趋 势虽然与中粉砂组分、粗粉砂组分和中值粒径的变化趋势一致,但是砂组分含量的变化波动性更高. 因为本 
研究的采样位置接近湖心 (图 1), 而粗颗粒物质可能只有在强降雨条件下才会被搬运到湖心. 因此,推测湖 光岩沉积物砂组分含量的变化可能指示了湛江地区的强降雨事件. 然而, 中值粒径的变幅明显小于 $550^{\circ} \mathrm{C}$ 烧 失量和与 Ti 元素含量的变幅, 这可能是指标之间不同的环境影响机制造成的. 中值粒径主要受降雨量控制, $550^{\circ} \mathrm{C}$ 烧失量更多地代表了水、热组合或者说是有效湿度的变化, 而 $\mathrm{Ti}$ 元素含量与降雨量和流域植被都有 关. 此外, 全新世湖光岩沉积物的沉积速率波动较大 ${ }^{[7]}$, 尤其是 6000 a B.P. 之后外源碎屑物质输人显著增 加 ${ }^{[11]}$, 放大了 $550^{\circ} \mathrm{C}$ 烧失量下降的信号, 这也可能是 $550^{\circ} \mathrm{C}$ 烧失量变幅比中值粒径变幅大的原因之一. 全新 世早期的沉积物粒径最粗, 反映了这一阶段的降雨量高, 气候湿润; 全新世中期逐渐降低的沉积物粒径反映 了降雨量降低, 气候转干; 全新世晚期, 沉积物粒径明显降低, 反映了降雨量大幅度降低, 气候迅速转干.

\section{2 湖光岩地区全新世以来古环境演化的几个阶段}

根据各粒级组分含量、中值粒径、 $550^{\circ} \mathrm{C}$ 烧失量和 $\mathrm{Ti}$ 元素含量的变化趋势, 可以将湖光岩地区全新世以 来的气候演化过程大致分为以下几个阶段:

(全新世早期: $10406-6085$ a B.P.) : 湖光岩玛珥湖沉积物粒径最粗, $550^{\circ} \mathrm{C}$ 烧失量最高, $\mathrm{Ti}$ 元素含量最 低, 反映了当时季风强盛, 降雨量高, 气候温暖湿润, 湖泊处于高水面, 流域内的植被覆盖好, 地表侵蚀较弱, 沉积物的径流输人比例低.

(全新世中期: $6085-3600$ a B.P.) : 沉积物粒径变细, $550^{\circ} \mathrm{C}$ 烧失量显著降低, $\mathrm{Ti}$ 元素含量升高, 说明湛 江地区自全新世中期季风减弱, 降雨量降低,气候逐渐变冷、变干, 湖泊水面降低, 流域内的植被退化,地表 侵蚀增强, 沉积物的径流输人比例增加.

(全新世晚期: 3600 a B.P. 至今) : 沉积物粒径持续变细, $550^{\circ} \mathrm{C}$ 烧失量持续降低, $\mathrm{Ti}$ 元素含量大幅度升 高, 指示湛江地区全新世晚期季风的大幅度减弱, 降雨量显著降低, 气候显著变冷、变干, 湖泊水面持续降 低,流域内的植被显著退化,地表侵蚀强度加大,沉积物的径流输人比例显著增加.

\section{3 讨论}

湖光岩玛珥湖沉积物粒度参数、 $550^{\circ} \mathrm{C}$ 烧失量、 $\mathrm{Ti}$ 元素含量变化指示湛江地区全新世早期季风强盛、降 雨量高, 为气候适宜期, 湖光岩流域内植被覆盖好; 全新世中期季风开始减弱, 降雨量减少,气候逐渐干旱 化, 流域植被开始退化; 全新世晚期季风迅速减弱, 降雨量大幅度降低, 气候持续变干、变冷, 流域植被显著 退化. 本研究得到的湖光岩全新世季风演化格局与王淑云等利用植物狍粉数据恢复的湖光岩全新世气候环 境演化格局是一致的 ${ }^{[5]}$, 只是本研究记录的中全新世季风迅速减弱发生在大约 6085 a B.P., 而王淑云等 ${ }^{[5]}$ 记录的中全新世季风迅速减弱发生于 7800 a B.P.. 王淑云等 ${ }^{[5]}$ 的年代框架缺乏 $8300-3800$ a B.P.之间的年 代控制点, 所以对中全新世气候转型期这个关键时间点的控制不够准确, 而我们利用的年代框架很好地弥 补了这个缺陷 ${ }^{[6]}$. 湖光岩玛珥湖沉积物记录的 6000 a B.P. 左右的中全新世季风减弱时间与定南泥炭 ${ }^{[23]}$ 、青 藏高原湖泊沉积物 ${ }^{[24]}$ 、西非岸外大西洋海洋沉积物 ${ }^{[25]}$ 和北美的湖泊沉积物 ${ }^{[26]}$ 记录的中全新世季风减弱时 间一致 (图 4), 体现了湛江地区全新世季风演化的全球性 ${ }^{[27]}$.

湛江地处亚热带地区, 受厄尔尼诺 $(\mathrm{ENSO})$ 和季风等低纬过程的影响明显, 厄尔尼诺年登陆的热带气旋 和台风减少 ${ }^{[28]}$, 降雨量减少. 南美的湖泊沉积物记录显示 ENSO 活动强度在早全新世非常微弱, 8000 a B.P. 以后开始抬升, 尤其是 6000 a B.P. 左右以后迅速增强 ${ }^{[29]}$. 湖光岩沉积物显示湛江地区早全新世季风强, 6085 a B.P.之后季风迅速减弱, 降雨量下降, 气候干旱化. 虽然降雨量与 ENSO 强度之间并不存在一一对应的关 系, 但是 ENSO 活动较强的阶段降雨变率增大 ${ }^{[30]}$. 海南岛记录也显示 2700 a B.P. 左右气候变化可能和 ENSO 活动有关 ${ }^{[31]}$, 这说明华南地区晚全新世以来的气候变化与 ENSO 系统存在着一定的联系. 因此, 湛江地区全 新世中后期的季风减弱、气候逐渐转干很可能与 ENSO 活动增强有关.

2000 a B.P.至今,各粒级组分含量、中值粒径 $550^{\circ} \mathrm{C}$ 烧失量和 $\mathrm{Ti}$ 元素含量都发生了相对较大幅度的变 化, 沉积速率明显增加 ${ }^{[7]}$, 孢粉记录也显示 2000 a B.P. 左右禾本科花粉含量明显增多 ${ }^{[5]}$. 除了气候因素的作 用外, 人类活动的影响也不可忽视. 人类活动的增强使得流域内的植被覆盖程度变差, 侵蚀能力加强, 径流 输人增加. 因此,2000 a B.P.至今的环境指标变化可能是受气候因素和人类活动的叠加影响.

\section{5 结论}

粒度频率特征曲线指示湖光岩玛珥湖沉积物外源输人部分主来自流域径流输人,大气降尘只占其中很 


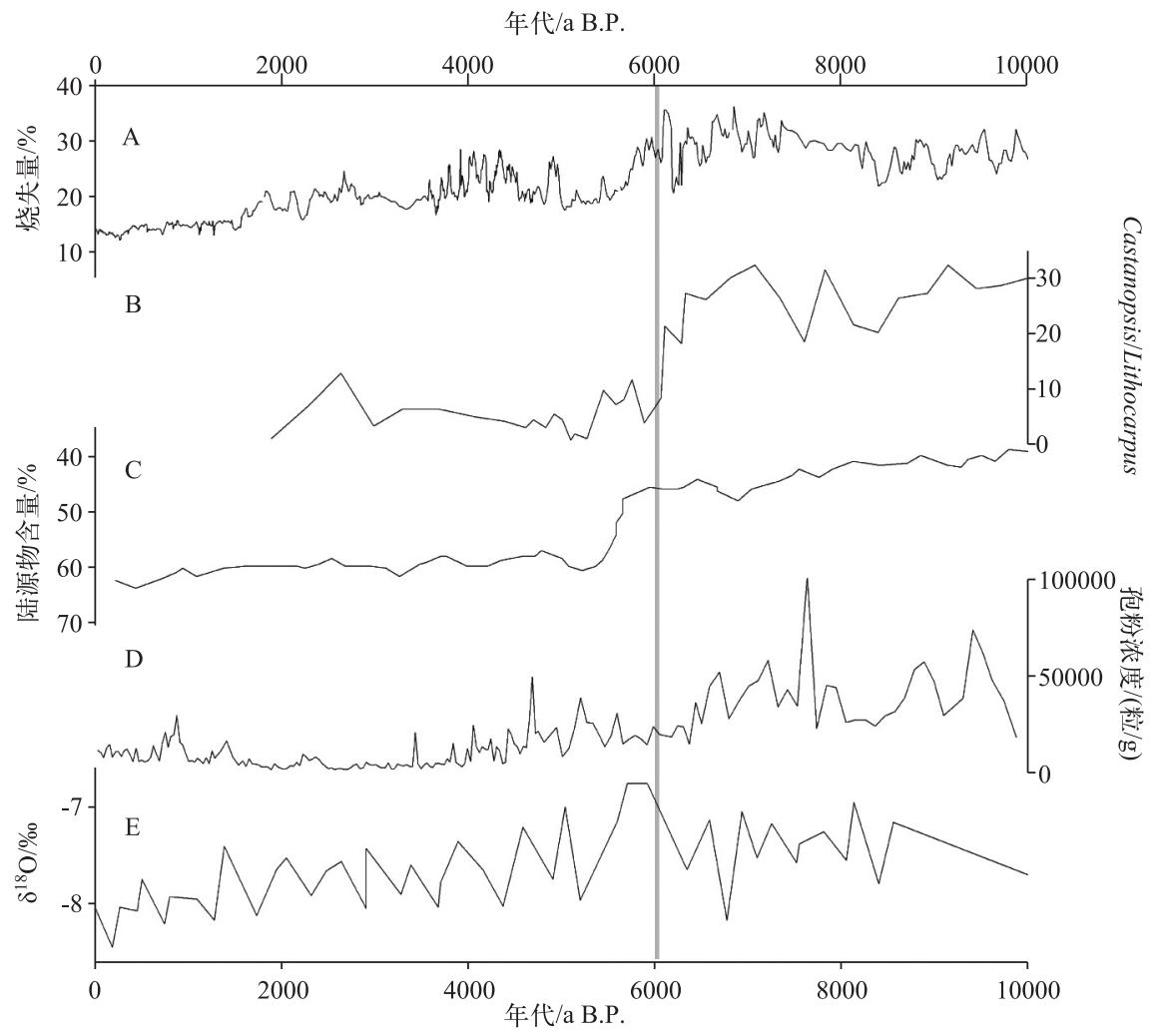

图 4 湖光岩玛珥湖沉积物 $550^{\circ} \mathrm{C}$ 烧失量 $(A)$ 与定南泥炭 ${ }^{[23]}(B)$ 、青藏高原湖泊沉积物 ${ }^{[24]}(\mathrm{C}) 、$ 西非岸外大西洋海洋沉积物 ${ }^{[25]}(\mathrm{D})$ 和北美的湖泊沉积物 ${ }^{[26]}(\mathrm{E})$ 记录的对比

Fig.4 Comparison among LOI $\left(550^{\circ} \mathrm{C}\right)$ of Huguanyan Maar Lake sediment (A), peat record from

$\operatorname{Dingnan}^{[23]}(\mathrm{B})$, lacustrine record from the Tibetan Plateau ${ }^{[24]}(\mathrm{C})$, marine record from

Atlantic near west Africa ${ }^{[25]}$ (D) and lacustrine record from the North America ${ }^{[26]}(\mathrm{E})$

小的一部分, 水动力是湖光岩沉积物的主要沉积动力. 湖光岩玛珥湖沉积物中值粒径与 $550^{\circ} \mathrm{C}$ 烧失量的正相 关、与 $\mathrm{Ti}$ 元素含量的负相关说明降雨量对湖光岩沉积物全新世粒度参数变化起主导作用,而湖泊水位波动 对湖光岩沉积物粒度变化的影响不大. 湖光岩沉积物较粗的粒径指示降雨量增加, 较细的粒径指示降雨量 降低,砂组分含量的变化指示了强降雨事件. 湛江地区全新世早期季风强盛, 降雨量高, 流域植被覆盖好, 沉 积物径流输人比例低; 6085 a B.P. 以后, 湛江地区季风持续减弱, 降雨量持续降低, 流域植被恶化, 沉积物径 流输人比例升高. 湖光岩沉积物记录的全新世中期季风迅速减弱的发生时间与全球很多地质载体记录的全 新世中期季风迅速减弱时间都非常接近,体现了湛江地区全新世季风演化的全球性. 湛江地区全新世中后 期的季风减弱、气候逐渐转干很可能与 ENSO 活动增强有关. 2000 a B.P. 以后, 粒度参数、 $550^{\circ} \mathrm{C}$ 烧失量和 Ti 元素含量的变幅明显增加与人类活动的影响有关,是人类活动和气候因素共同作用的结果. 致谢:感谢中国科学院南京地理与湖泊研究所的张恩楼和袁和忠在野外采样中给予的帮助.

\section{6 参考文献}

[ 1 ] Liu JQ, Lu HY, Negendank J et al. Periodicity of Holocene climatic variations in the Huguangyan Maar Lake. Chin Sci Bull, 2000, 45(18): 1712-1717.

[ 2 ] Chu GQ, Liu JQ, Sun Q et al. The 'Mediaeval Warm Period' drought recorded in Lake Huguangyan, tropical South China. The Holocene, 2002, 12: 511-516. 
[ 3 ] Fuhrmann A, Mingram J, Lücke A et al. Variations in organic matter composition in sediments from Lake Huguang Maar (Huguangyan), south China during the last $68 \mathrm{ka}$ : implications for environmental and climatic change. Organic Geochem, 2003, 34: 1497-1515.

[ 4 ] Mingram J, Schettler G, Nowaczyk N et al. The Huguang maar lake-a high-resolution record of palaeoenvironmental and palaeoclimatic changes over the last 78,000 years from South China. Quat Int, 2004, 122: 85-107.

[ 5 ] Wang SY, Lu HY, Liu JQ et al. The early Holocene optimum inferred from a high-resolution pollen record of Huguangyan Maar Lake in southern China. Chin Sci Bull, 2007, 52(20) : 2829-2836.

[ 6 ] Wu X, Zhang Z, Xu X et al. Asian summer monsoonal variations during the Holocene revealed by Huguangyan maar lake sediment record. Palaeogeogr Palaeoclim Palaeoecol, 2012, 323/324/325: 13-21.

[ 7 ] Yancheva G, Nowaczyk NR, Mingram J et al. Influence of the intertropical convergence zone on the East Asian monsoon. Nature, 2007, 445: 74-77.

[ 8 ] Zhou H, Guan H, Chi B. Records of winter monsoon strength. Nature, 2007, 450: E10-E11. DOI: 10. 1038/nature06408.

[ 9 ] Yancheva G, Nowaczyk NR, Mingram J. Replying to: Zhou H et al. Nature, 2007, 450: E11. DOI: 10.1038/nature06409.

[10] Zhou H, Wang BS, Guan H et al. Constraints from strontium and neodymium isotopic ratios and trace elements on the sources of the sediments in Lake Huguang Maar. Quat Res, 2009, 72(2) : 289-300.

[11] Shen J, Wu X, Zhang Z et al. Ti content in Huguangyan maar lake sediment as a proxy for monsoon induced vegetation density in the Holocene. Geophys Res Lett, 2013, 40: 1-7. DOI: 10.1002/grl.50740.

[12] Hou Xinhua, Wu Yanhong, Yang Liyuan. The paleo-precipitation history recorded by the characteristics of grain-size of Lake Jingpo during Holocene. J Lake Sci, 2006,18(6) :605-614 (in Chinese with English abstract). DOI: 10.18307/ 2006.0608. [ 侯新花, 吴艳宏, 杨丽原. 全新世镜泊湖粒度特征记录的该地区古降水变化历史. 湖泊科学, 2006, 18 (6) : 605-614.]

[13] Xiao JL, Porter SC, An ZS et al. Grain size of quartz as an indicator of winter monsoon strength on the Loess Plateau of central China during the last 130000 yr. Quat Res, 1995, 43(1) : 22-29.

[14] Sun Y, Lu H, An Z. Grain size of loess, palaeosol and Red Clay deposits on the Chinese Loess Plateau: Significance for understanding pedogenic alteration and palaeomonsoon evolution. Palaeogeogr Palaeoclim Palaeoecol, 2006, 241 : 129-138.

[15] Pedreros R, Howa HL, Michel D. Application of grain size trend analysis for the determination of sediment transport pathways in intertidal areas. Marine Geol, 1996, 135(1/2/3/4) : 35-49.

[16] Liu Xingqi, Wang Sumin, Shen Ji. The grainsize of the core QH-2000 in Qinghai Lake and its implication for paleoclimate and paleoenvironment. J Lake Sci, 2003, 15(2) :112-117 (in Chinese with English abstract). DOI: 10.18307/2003.0203. [刘兴起, 王苏民, 沈吉. 青海湖 QH-2000 钻孔沉积物粒度组成的古气候古环境意义. 湖泊科学, 2003, 15(2)： 112-117.]

[17] Wang Junbo, Zhu Liping. Grain-size characteristics and their paleo-environmental significance of Chen Co Lake sediments in southern Tibet. Prog in Geogra, 2002, 21 (5): 459-467(in Chinese with English abstract). [王君波, 朱立平. 藏南沉 错沉积物的粒度特征及其古环境意义. 地理科学进展, 2002, 21(5) : 459-467.]

[18] Wu Xudong, Shen Ji, Wang Yong. Holocene paleoenvironmental evolution of the Huguangyan maar lake. Marine geol \& Quat geol, 2011, 31(4) : 155-162 (in Chinese with English abstract). [ 吴旭东, 沈吉, 汪勇. 湖光岩玛珥湖沉积物反 映的全新世以来古环境演化. 海洋地质与第四纪地质, 2011, 31(4) : 155-162.]

[19] Pye K ed. A eolian dust and dust deposits. New York: Elsevier, 1987: 68.

[20] Sun Qianli, Zhou Jie, Xiao Jule. Grain-size characteristics of lake Daihai sediments and its palaeoenvironment significance. Marine Geol \& Quat Geol, 2001, 21(1) : 93-95(in Chinese with English abstract). [ 孙千里, 周杰, 肖举乐. 岱海沉积 物粒度特征及其古环境意义. 海洋地质与第四纪地质, 2001, 21(1) : 93-95.]

[21] Wang Yong, Shen Ji, Yang Xiangdong. Environmental changes deduced from grain-size characteristics of the sediments from Hongjiannao Lake, Shanxi Province. Acta Sedimentol Sin, 2006, 24(3): 349-355 (in Chinese with English abstract). [ 汪勇, 沈吉, 羊向东. 陕北红碱淖沉积物粒度特征所揭示的环境变化. 沉积学报, 2006, 24 (3) : 349-355.] 
[22] Wei Qiang, Han Jingtai, Li Dong. Grain-size characteristics and its palaeoenvironmental implications for a sediment core of Erlongwan from northeast China since 32 ka B. P. Quat Sci, 2008, 28(5) : 957-958( in Chinese with English abstract). [魏强, 汉景泰, 李东. 32 ka B. P. 以来东北二龙湾玛珥湖沉积序列的粒度特征及其古环境意义. 第四纪研究, 2008, 28(5) : 957-958.]

[23] Zhou WJ, Xie SC, Meyers PA. Reconstruction of late glacial and Holocene climate evolution in southern China from geolipids and pollen in the Dingnan peat sequence. Org Geochem, 2005, 36:1272-1284.

[24] Shen J, Liu X, Wang S et al. Palaeoclimatic changes in the Qinghai Lake area during the last 18,000 years. Quat Int, 2005, 136:131-140.

[25] DeMenocal PB. Plio-Pleistocene African climate. Science, 1995, 270: 53-59.

[26] Zhao C, Yu Z, Ito E et al. Holocene climate trend, variability, and shift documented by lacustrine stable isotope record in the northeastern United States. Quat Sci Rev, 2010, 29: 1831-1843.

[27] Wang PX. Global monsoon in a geological perspective. Chin Sci Bull, 2009, 54(7) : 1113-1136.

[28] Huang Jing. Impact of ENSO on the tropical cyclones affecting Guangdong. Meteor Monthly, 2006, 32(9): 55-59(in Chinese with English abstract).[黄静. 影响广东的热带气旋与 ENSO 的关系. 气象, 2006, 32(9): 55-59.]

[29] Moy CM, Seltzer GO, Rodbell DT et al. Variability of El Niño/Southern Oscillation activity at millennial timescales during the Holocene epoch. Nature, 2002, 420: 162-165.

[30] Liu Yongqiang, Ding Yihui. Reappraisal of the influence of ENSO events on seasonal precipitation and temperature in China. Sci Atmosp Sini, 1995, 19(2) : 200-207( in Chinese with English abstract). [ 刘永强, 丁一汇. ENSO 事件对我国季 节降水和温度的影响. 大气科学, 1995, 19(2) : 200-207.]

[31] Zheng Z, Wang J, Wang B et al. High-resolution records of Holocene from the Shuangchi Maar Lake in Hainan Island. Chin Sci Bull, 2003, 48(5): 497-502. 